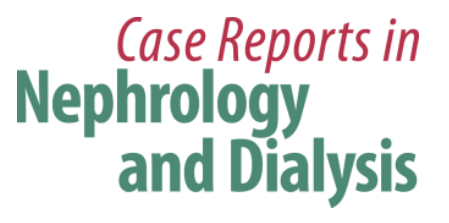

Case Rep Nephrol Dial 2017;7:26-33

DOI: $10.1159 / 000468517$

Publisned onIIne: April Z0, 2017

(c) 2017 The Author(s)

Published by S. Karger AG, Basel

www.karger.com/cnd

This article is licensed under the Creative Commons Attribution-NonCommercial 4.0 International License (CC BY-NC) (http://www.karger.com/Services/OpenAccessLicense). Usage and distribution for commercial purposes requires written permission.

\title{
A Case of Fibrillary Glomerulonephritis with Fibril Deposition in the Arteriolar Wall and a Family History of Renal Disease
}

\author{
Kentaro Watanabe ${ }^{a}$ Kentaro Nakai ${ }^{a, b}$ Nozomi Hosokawa ${ }^{a}$ \\ Shuhei Watanabe ${ }^{a}$ Keiji Kono ${ }^{a}$ Shunsuke Goto $^{a}$ Hideki Fujii $^{a}$ \\ Shigeo Hara ${ }^{c}$ Shinichi Nishi ${ }^{a}$ \\ ${ }^{a}$ Division of Nephrology and Kidney Center, Kobe University Graduate School of \\ Medicine, Kobe, Japan; ${ }^{b}$ Department of Nephrology and Kidney Center, Kakogawa Central \\ City Hospital, Kakogawa, Japan; 'Department of Diagnostic Pathology, Kobe University \\ Graduate School of Medicine, Kobe, Japan
}

\section{Keywords}

Fibrillary glomerulonephritis - Familial nephritis - Hereditary nephritis · Nephrotic syndrome

\begin{abstract}
Herein, we report a case of fibrillary glomerulonephritis (FGN). FGN usually shows nonamyloidal fibrils in the mesangium and glomerular capillary walls on electron microscopy. Inherited cases of FGN have been reported in only 3 families, and the suspected genetic form was autosomal dominant. In the present case, the deposition of microfibrils in the arteriolar wall as well as the glomerulus is unique. Our patient's father died of nephrotic syndrome, and his elder brother had a biopsy-proven glomerulopathy. The histological findings of the brothers are similar to mesangial proliferative glomerulonephritis and resemble each other.
\end{abstract}




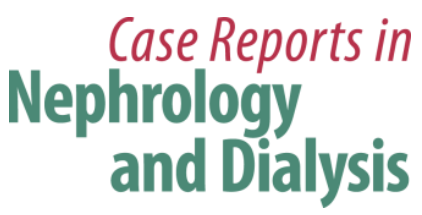

Case Rep Nephrol Dial 2017;7:26-33

Therefore, our case is presumed to be familial FGN. Additionally, herein, we review the literature and reconsider the histological and clinical characters of FGN.

(C) 2017 The Author(s)

Published by S. Karger AG, Basel

\section{Background}

Nephrotic syndrome with the deposition of non-amyloidal fibril structures in the glomeruli was first reported in 1977 by Rosenmann et al. [1], and the term "fibrillary glomerulonephritis" (FGN) has been used since 1987 [2]. FGN is a rare glomerular deposition disease and accounts for approximately $0.5-1.0 \%$ of all adult glomerulonephritis cases on renal biopsy [3-6]. It is characterized by the deposition of microfibrils - 10-30 nm in diameter - in the mesangial and/or glomerular capillary walls. Congo red stain shows a negative reaction [3-6]. On immunofluorescent study, immunoglobulin G (IgG) and C3 reveal dominant intraglomerular depositions [3-6]. IgG4 is predominantly positive in the staining for subclasses of IgG [1, 3-6]. FGN usually develops at middle or older age [5, 6], and the typical clinical findings are proteinuria, which often reaches the nephrotic range. Treatment with steroids and immunosuppressive agents is not effective, and the renal outcome is generally poor [3-7]. Although a few familial cases have been reported in the past $[8,9]$, the clinical and pathological features were not fully evaluated. Herein, we report a patient with FGN and a family history of renal disease, and we compare the histological and clinical features with those of previous familial FGN.

\section{Case Presentations}

Our patient (Case 1) is a 40-year-old Japanese man. His 42-year-old brother (Case 2) had glomerulopathy. Their father (Case 3) had already died of nephrotic syndrome but did not undergo renal biopsy. In the pedigree analysis (Fig. 1), Case 1's children had no medical history on routine school medical checkup. No other relatives had renal disease. The brothers' paternal uncle was diagnosed with rheumatoid arthritis, and their paternal grandfather had a history of cerebral infarction.

\section{Case 1}

Case 1 was originally healthy, and there was no abnormality in urinalysis at a young age. Proteinuria was first detected 5 years ago during a medical checkup. Proteinuria (1+ on dipstick test) was detected annually thereafter, but the patient was not referred to the hospital for specialist evaluation at that time. He was referred to a nearby hospital at 40 years of age and underwent a more detailed examination by renal biopsy at our department. He had no complicating diseases excluding a history of renal diseases.

Physical examination revealed no hypertension or pretibial edema at the time of admission. His urine protein excretion was $1.33 \mathrm{~g} / \mathrm{g} \mathrm{Cr}$ without microscopic hematuria, and serum creatinine was $66.3 \mu \mathrm{mol} / \mathrm{L}$. The titers of antinuclear antibody, complements, and immunoglobulins were within normal limits. Serological tests for hepatitis B or C virus were both 


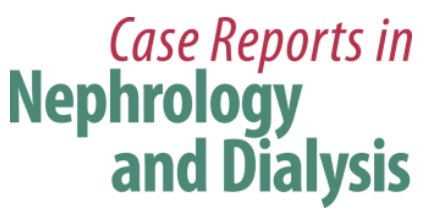

Case Rep Nephrol Dial 2017;7:26-33

DOI: $10.1159 / 000468517$

Watanabe et al.: A Case of Fibrillary Glomerulonephritis with Fibril Deposition in the Arteriolar Wall and a Family History of Renal Disease

negative. On light microscopy, 90 glomeruli were observed, and no global or segmental sclerosis was detected. All glomeruli showed mild mesangial expansion and segmental thickening of the glomerular capillary wall (Fig. 2). Elastofibrosis in the interlobular arterial tissue was observed, whereas arteriolar hyalinosis was not observed. Congo red staining was negative, and positive apple green color was not detected under polarized light. Immunofluorescence showed IgG and C3 depositions in the mesangium and glomerular capillary walls; additionally, the vessel walls showed strong IgG and C3 depositions and mild IgM and C1q depositions. IgA and lambda were negative, and kappa was very slightly positive in the glomeruli. Electron microscopy revealed electron-dense deposits with randomly arranged nonbranching fibrils, measuring approximately $20 \mathrm{~nm}$ in diameter in the mesangial lesion and glomerular basement membranes (Fig. 3). We confirmed fibrils in the arteriolar basement membrane on electron microscopy.

The patient was diagnosed with FGN, and treatment with $50 \mathrm{mg}$ of oral losartan potassium once daily was initiated. Serum creatinine was stable, and the excretion of urine protein was decreased to $0.53 \mathrm{~g} / \mathrm{g} \mathrm{Cr} 7$ months after the start of therapy.

\section{Case 2}

Case 2 had no significant medical history in his annual medical checks. At 34 years of age, mild proteinuria first appeared in the urinalysis. The dipstick test for occult blood was also positive at a later annual urinalysis; thus, he was admitted to a nearby hospital for renal biopsy.

He had no hypertension or edema at the time of admission and urine protein excretion was $2.0 \mathrm{~g} /$ day without microscopic hematuria. Serum creatinine was $61.9 \mu \mathrm{mol} / \mathrm{L}$. Immunological tests including antinuclear antibody, complements, and immunoglobulins were not specific, and hepatitis B or C viral tests were also negative. On light microscopy, 49 glomeruli were observed but no global or segmental sclerosis was observed, and there was diffuse mesangial matrix expansion, along with partial double contour of the glomerular basement membranes (Fig. 2). Tubular atrophy and interlobular arterial sclerosis were very mild, whereas arteriolar hyalinosis was negative. On immunofluorescence, mild IgG and IgM, and strong C3 depositions were observed in the mesangium and capillary walls. Electron microscopy was not performed.

He was diagnosed with membranoproliferative glomerulonephritis (MPGN) and treated with prednisolone and cyclophosphamide. Two years later, this combination therapy was discontinued because the treatment was ineffective, and imidapril $5 \mathrm{mg} /$ day was prescribed after that. Five years after his biopsy, his urine protein excretion was $1.68 \mathrm{~g} /$ day, and serum creatinine was $70.7 \mu \mathrm{mol} / \mathrm{L}$.

Case 3

Case 3 died with nephrotic syndrome at the age of 42 years. He did not undergo renal biopsy, and, unfortunately, the medical records have been lost. 


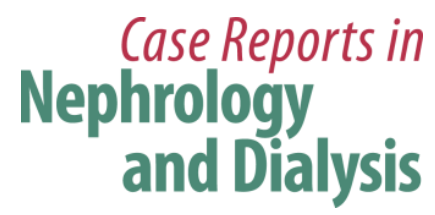

Case Rep Nephrol Dial 2017;7:26-33

DOI: $10.1159 / 000468517$

Watanabe et al.: A Case of Fibrillary Glomerulonephritis with Fibril Deposition in the

Arteriolar Wall and a Family History of Renal Disease

\section{Discussion}

Case 1 was positively diagnosed with FGN according to the electron microscopy findings. The unique point was the deposition of microfibrils with $20 \mathrm{~nm}$ in diameter in the basement membranes of the arteriolar wall. Fibrils of FGN are typically found in the mesangium and glomerular basement membranes with or without subepithelial and subendothelial electron-dense deposits [4-6, 10-12]. In a few previous reports, fibril structures were noticed in the tubular basement membranes by electron microscopy, whereas arteriolar deposition was not confirmed [4-6, 10-12]. Although the pathophysiology of the fibrillary deposition is still unknown, the histopathological features suggest that the fibrils might be derived from immunoglobulins and have an affinity to the extracellular matrix $[4,5,9,13]$. It may be natural that fibrils deposit in the basement membrane of the arteriolar wall in FGN.

FGN exhibits various glomerular changes, including MPGN, mesangial proliferative glomerulonephritis (MesPGN), and membranous glomerulonephritis [3-6]. Some individuals with FGN have background diseases such as hepatitis $\mathrm{C}$ virus infection, polyclonal gammopathy, and lymphoproliferative disorders $[5,6,14,15]$. From the above, FGN is verified to be a secondary glomerular nephritis. Table 1 shows previously published familial cases $[8,9]$. In this summary, the histological patterns comprised MGPN, MesPGN, and membranous glomerulonephritis. In our cases as well as in previous familial cases, there were no comorbidities such as infectious, autoimmune, or malignant diseases in their history. The glomerular changes of Case 1 and Case 2 were thought to be more comparable to MesPGN than MPGN, and there were no secondary causes that would induce MesPGN. Their pathological findings were closely similar on light microscopy as well as immunofluorescence. Therefore, FGN was presumed to be the clinical diagnosis in the case of the elder brother (Case 2), although electron microscopy was not performed and this is a limitation in our report.

Familial incidence of FGN has been reported in a limited number of case reports. The variety of inherited pathways, including father to son, father to daughter, and mother to son, was confirmed in the previous reports [8, 9]; therefore, an autosomal dominant genetic form is suspected. FGN develops at 40-60 years of age; thus, patients with FGN could procreate in their reproductive years.

Herein, we reported a very rare case of FGN with fibril deposition in the arteriolar wall and possible cases of familial incidence. To clarify the etiology and effective therapy for FGN, we have to accumulate more cases.

\section{Acknowledgements}

This study was supported in part by a Grant-in-Aid for Intractable Renal Diseases Research, Research on Rare and Intractable Diseases, and Health and Labour Sciences Research Grants from the Ministry of Health, Labour and Welfare of Japan and in part by a Grant-inAid for Research on Ideal Treatment Methods for the Prevention of Progression of Chronic Kidney Disease, Practical Research for Kidney Diseases, and Health and Labour Sciences Research Grants from the Ministry of Health, Labour and Welfare of Japan.

The results presented in this report have not been published previously, in whole or part, except in abstract form. 


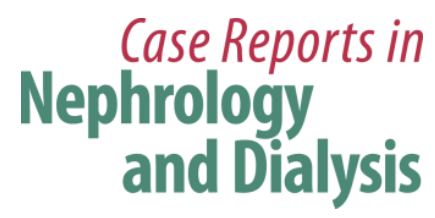

Case Rep Nephrol Dial 2017;7:26-33

\section{Statement of Ethics}

The authors have no ethical conflicts to disclose.

\section{Disclosure Statement}

The authors have no conflicts of interest to disclose.

\section{References}

1 Rosenmann E, Eliakim M: Nephrotic syndrome associated with amyloid-like glomerular deposits. Nephron 1977;18:301-308.

2 Alpers CE, Rennke HG, Hopper J Jr, Biava CG: Fibrillary glomerulonephritis: an entity with unusual immunofluorescence features. Kidney Int 1987;31:781-789.

-3 Fogo A, Qureshi N, Horn RG: Morphologic and clinical features of fibrillary glomerulonephritis versus immunotactoid glomerulopathy. Am J Kidney Dis 1993;22:367-377.

4 Iskandar SS, Falk RJ, Jennette JC: Clinical and pathologic features of fibrillary glomerulonephritis. Kidney Int 1992;42:1401-1407.

5 Rosenstock JL, Markowitz GS, Valeri AM, Sacchi G, Appel GB, D’Agati VD: Fibrillary and immunotactoid glomerulonephritis: distinct entities with different clinical and pathologic features. Kidney Int 2003;63:1450-1461.

6 Alpers CE, Kowalewska J: Fibrillary glomerulonephritis and immunotactoid glomerulopathy. J Am Soc Nephrol 2008;19:34-37.

7 Hogan J, Restivo M, Canetta P, et al: Rituximab treatment for fibrillary glomerulonephritis. Nephrol Dial Transplant 2014;29:1925-1931.

Ying T, Hill P, Desmond M, Agar J, Mallett A: Fibrillary glomerulonephritis: an apparent familial form? Nephrology 2015;20:506-509.

Chan T, Chan K: Fibrillary glomerulonephritis in siblings. Am J Kidney Dis 1998;31:e4.1-e4.5.

Nasr S, Valeri A, Cornell L, et al: Fibrillary glomerulonephritis: a report of 66 cases from a single institution. Clin. J Am Soc Nephrol 2011;6:775-784.

11 Javaugue V, Karras A, Glowacki F, et al: Long-term kidney disease outcomes in fibrillary glomerulonephritis: a case series of 27 patients. Am J Kidney Dis 2013;62:679-690. Iskandar SS, Herrera GA: Glomerular disease with organized deposits; in Jennette JC, D'Agati VD, et al. (eds): Heptinstall's Pathology of the Kidney 7th Grades. Alphen Aan Den Rijn, Wolters Kluwer, 2014, pp 1015-1021.

13 Yang GC, Nieto R, Stachura I, Gallo GR: Ultrastructural immunohistochemical localization of polyclonal IgG, C3, and amyloid P component on the congo red-negative amyloid-like fibrils of fibrillary glomerulopathy. Am J Pathol 1992;141:409-419.

14 Grove P, Neale PH, Peck M, Schiller B, Haas M: Monoclonal immunoglobulin G1-kappa fibrillary glomerulonephritis. Mod Pathol 1998;11:103-109.

15 Guerra G, Narayan G, Rennke HG, Jaber BL: Crescentic fibrillary glomerulonephritis associated with hepatitis C viral infection. Clin Nephrol 2003;60:364-368. 


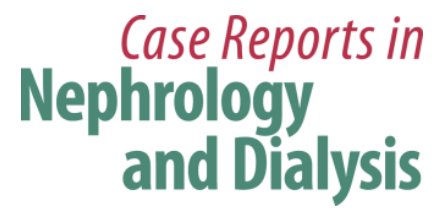

Case Rep Nephrol Dial 2017;7:26-33

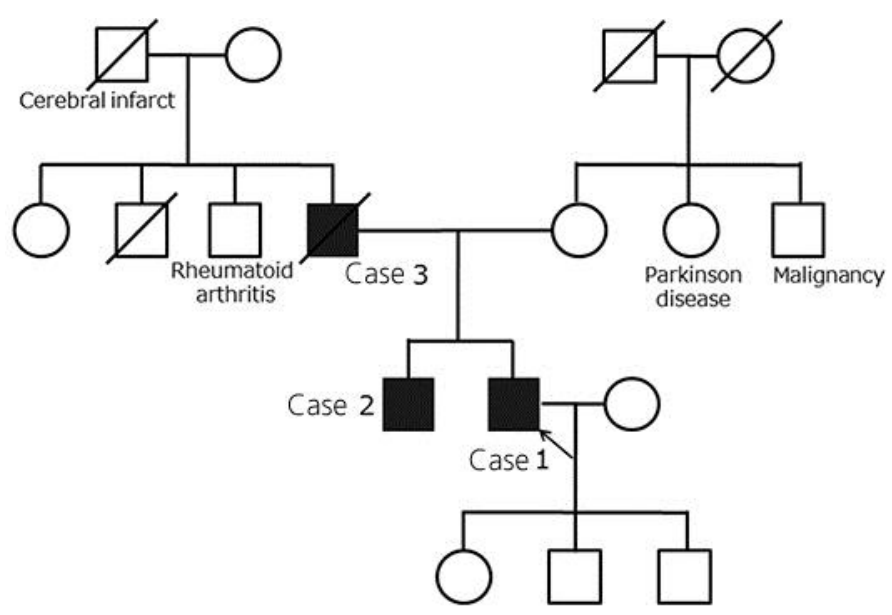

Fig. 1. Family pedigree. Our patient (Case 1) is a 40 -year-old Japanese man. His 42 -year-old brother (Case 2) had glomerulopathy. Their father (Case 3) had already died of nephrotic syndrome but did not undergo renal biopsy. Case 1 has 3 children who have no medical histories, and Case 2 has no offspring. There are no other family histories of kidney diseases. A black square stands for a patient with probable or definite fibrillary glomerulonephritis.

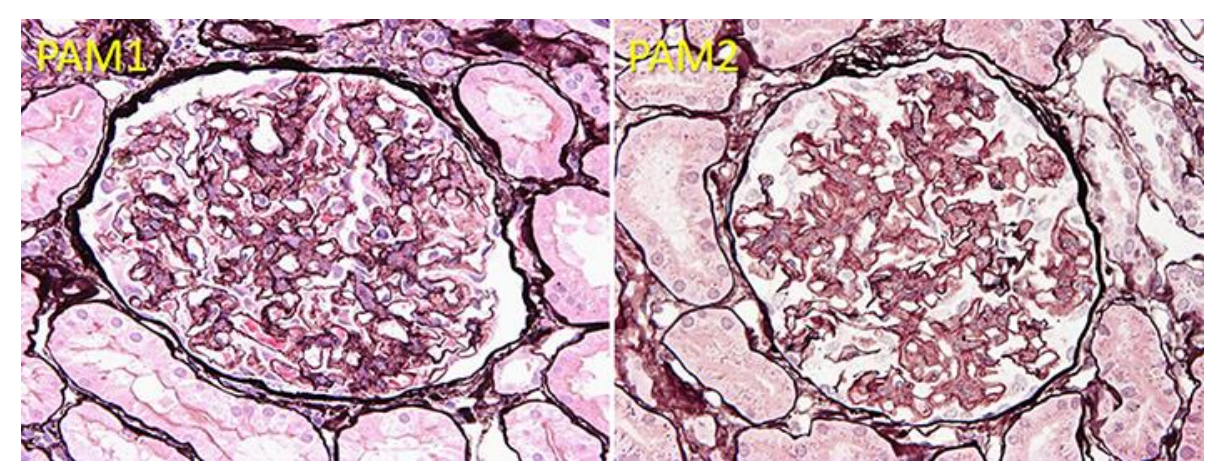

Fig. 2. Light microscopic findings of Case 1 and Case 2. Periodic acid methenamine (PAM) silver stain of Case 1 (PAM1) and Case 2 (PAM2) show mesangial expansion and glomerular capillary wall thickening with double contour formation localized to only a small part of the glomerulus. 


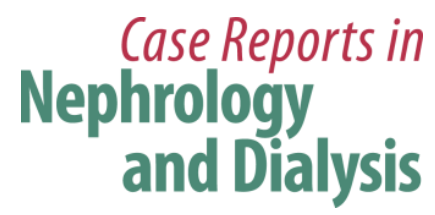

Case Rep Nephrol Dial 2017;7:26-33

DOI: $10.1159 / 000468517$

(C)

(C) 2017 The Author(s). Published by S. Karger AG, Basel www.karger.com/cnd

Watanabe et al: A Case of Fibrillary Glomerulonephritis with Fibril Deposition in the Arteriolar Wall and a Family History of Renal Disease

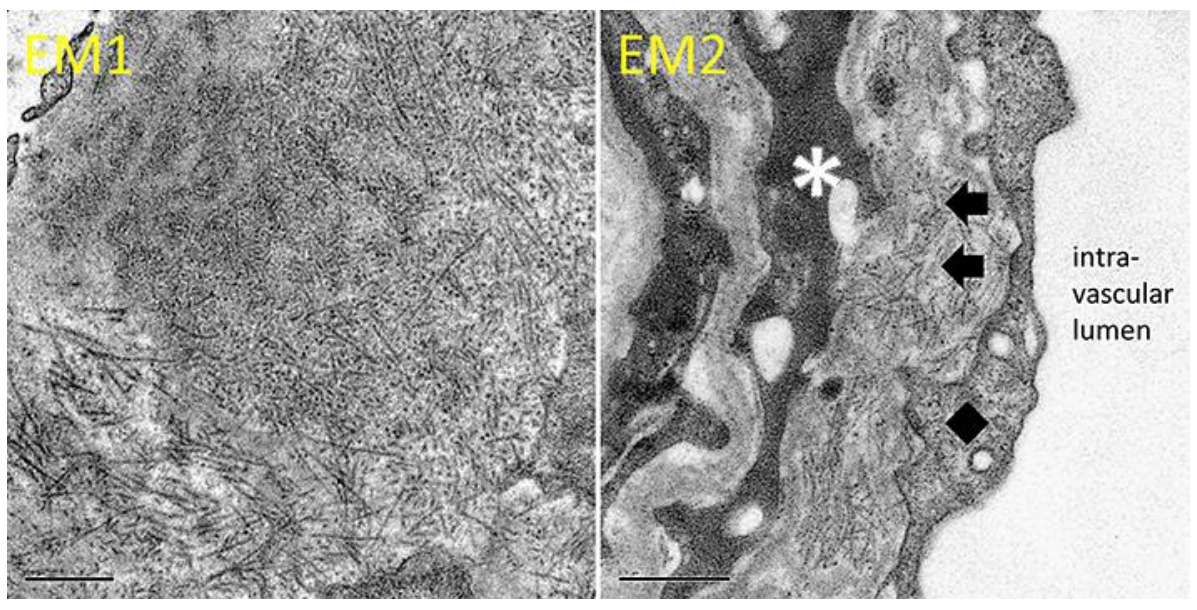

Fig. 3. Electron microscopic findings of Case 1. Electron microscopic images show electron-dense deposits, composed of randomly arranged nonbranching fibrils, measuring approximately $20 \mathrm{~nm}$ in external diameter (EM1), in the arteriolar basement membrane as well as mesangial lesion and glomerular basement membrane. EM2 shows fibrillary deposits (black arrows) in the arteriolar basement membrane. The asterisk and black square indicate a smooth muscle cell and vascular endothelium, respectively. Bars in EM1 (original magnification $\times 40,000$ ) and EM2 (original magnification $\times 50,000$ ) are $500 \mathrm{~nm}$. 


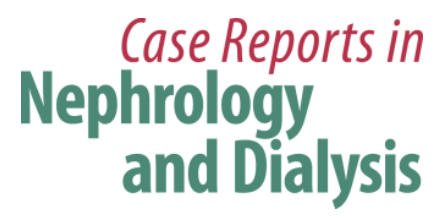

Case Rep Nephrol Dial 2017;7:26-33

Watanabe et al.: A Case of Fibrillary Glomerulonephritis with Fibril Deposition in the Arteriolar Wall and a Family History of Renal Disease

Table 1. List of characteristics of fibrillary glomerulonephritis developing within a family in previous studies and our report

\begin{tabular}{|c|c|c|c|c|c|c|c|c|c|c|c|}
\hline \multirow[t]{2}{*}{$\begin{array}{l}\text { Family } \\
\text { No. }\end{array}$} & \multirow[t]{2}{*}{ Relationship } & \multirow{2}{*}{$\begin{array}{l}\text { Age at } \\
\text { disease } \\
\text { onset, } \\
\text { years }\end{array}$} & \multicolumn{2}{|c|}{ Change in $\mathrm{Cr}$} & \multirow[t]{2}{*}{$\begin{array}{l}\text { Initiation of } \\
\text { RRT }\end{array}$} & \multirow[t]{2}{*}{ Treatment } & \multirow[t]{2}{*}{$\begin{array}{l}\text { LM } \\
\text { findings }\end{array}$} & \multirow[t]{2}{*}{$\begin{array}{l}\text { Positive staining } \\
\text { on IF }\end{array}$} & \multicolumn{3}{|c|}{$\begin{array}{l}\text { Location of } \\
\text { fibrils on EM }\end{array}$} \\
\hline & & & at baseline & at follow-up & & & & & Mes & GBM & $\mathrm{ABM}$ \\
\hline \multirow[t]{2}{*}{$1[8]$} & Older brother & 34 & 77.8 & 72.5 & 38 months & $\begin{array}{l}\text { RASI, PSL, } \\
\text { CPA, AZA }\end{array}$ & MPGN & IgG, C3, C1q, Lambda & + & + & \\
\hline & Younger sister & 32 & 120.2 & 114.9 & 22 months & $\begin{array}{l}\text { RASI, PSL, } \\
\text { CPA, AZA }\end{array}$ & MPGN & $\begin{array}{l}\text { IgG, IgM, C3, Kappa, } \\
\text { Lambda }\end{array}$ & + & & \\
\hline \multirow[t]{2}{*}{$2[9]$} & Mother & 61 & 80.4 & & HD; 5 years & RASI & MPGN+MN & IgG, IgM, C3, C1q & + & + & \\
\hline & Son & 40 & 70.7 & 103.4 & 5 years & RASI & MPGN+MN & C1q, Lambda & + & + & \\
\hline \multirow[t]{2}{*}{3 [9] } & Father & 64 & 102.5 & & PD; 18 months & RASI & MesPGN & IgG, Kappa, Lambda & + & + & \\
\hline & Daughter & 43 & 208.6 & 222.8 & 10 months & $\begin{array}{l}\text { RASI, PSL, } \\
\text { CPA }\end{array}$ & MesPGN & $\begin{array}{l}\text { IgG, IgA, IgM, C3, } \\
\text { C1q, Kappa, Lambda }\end{array}$ & + & + & \\
\hline \multirow{3}{*}{$\begin{array}{l}4 \\
\text { (our } \\
\text { cases) }\end{array}$} & Father & NA & NA & NA & & NA & NA & NA & NA & NA & NA \\
\hline & Older brother & 34 & 70.7 & 70.7 & 5 years & $\begin{array}{l}\text { PSL, CPA, } \\
\text { RASI }\end{array}$ & MesPGN & IgG, IgM, C3 & NA & NA & NA \\
\hline & $\begin{array}{l}\text { Younger } \\
\text { brother }\end{array}$ & 35 & 66.3 & 66.3 & 7 months & RASI & MesPGN & IgG, IgM, C3, C1q & + & + & + \\
\hline
\end{tabular}

Numbers in square brackets indicate references from which the data were taken.

$\mathrm{Cr}$, serum creatinine (measured in $\mu \mathrm{mol} / \mathrm{L}$ ); RRT, renal replacement therapy; LM, light microscopic; IF, immunofluorescence; EM, electron microscopy; GBM,

glomerular basement membrane; ABM, arteriolar basement membrane; RASI, renin-angiotensin-aldosterone system blocker; PSL, prednisolone; CPA,

cyclophosphamide; AZA, azathioprine; HD, hemodialysis; PD, peritoneal dialysis; MPGN, membranoproliferative glomerulonephritis; MN, membrane nephropathy;

MesPGN, mesangial proliferative glomerulonephritis; Mes, mesangial lesion; NA, not available; Ig, immunoglobulin. 